\title{
Small and Beautiful? The Programme of Activities and the Least Developed Countries*
}

\author{
Patrick Bayer ${ }^{\dagger}$ \\ University of Mannheim
}

\author{
Valerie M. Pinkerton \\ Environmental Law Institute
}

February 25, 2016

\author{
Johannes Urpelainen \\ Columbia University
}

2 February 2014

\begin{abstract}
Most carbon abatement projects under the Kyoto Protocol's Clean Development Mechanism (CDM) have been implemented in rapidly industrializing countries, notably China and India. To support small carbon abatement projects and to promote decarbonization in the least developed countries, the Programme of Activities (PoA) modality was introduced. But are the determinants of project implementation different under the PoA from those for conventional CDM projects? To answer this question, we conduct a statistical analysis of the global distribution of CDM projects and PoAs during the years 2007-2012. In regard to country size, large countries clearly dominate both the CDM and PoA, suggesting that the PoA may do only little to facilitate project implementation in small countries. However, the number of PoAs has a strong negative association with the proportion of a country's corruption level, while the importance of corruption for the CDM is much smaller. Moreover, per capita income has no effect on PoA implementation, while high wealth levels have a weak positive effect on CDM projects. Thus, the PoA modality seems to promote sustainable development in poor countries that have exceeded a certain threshold of good governance. In this regard, PoAs are directing carbon credits to new areas, as many had initially hoped.
\end{abstract}

\footnotetext{
*We thank Narayan Subramanian and Patrick Woolsey for insightful comments on a previous draft.

${ }^{\dagger}$ Corresponding author. University of Mannheim, School of Social Sciences, Department of Political Science. D7, 27, 68131 Mannheim, Germany. Email: pbayer@mail.uni-mannheim.de. Phone: +49-161-181-2418.
} 


\section{Introduction}

The Kyoto Protocol's Clean Development Mechanism (CDM) is a flexibility mechanism that allows industrialized countries to substitute credits from carbon abatement projects in developing countries for domestic emissions reductions. In practice, the vast majority of CDM projects have been implemented in rapidly industrializing countries, notably China and India. In contrast, small and poor countries in Sub-Saharan Africa and elsewhere have implemented few CDM projects (Okubo and Michaelowa, 2010; Castro and Michaelowa, 2011). For example, of the 8,815 CDM projects included in the CDM/JI Pipeline during the years 2007-2012, when the CDM was most active, only 201 (2.3\%) are hosted in Africa. ${ }^{1}$ Only South Africa (48 projects) and Kenya (25 projects) were on the list of top 20 countries hosting the largest number of CDM projects, while large African countries with potential for CDM projects, such as Ghana and Zambia, were home to less than four CDM projects. Scholars have noted that the observable bias against the least developed countries (LDCs) is related to a lack of institutional capacity, which means that the cost of CDM project implementation outside large economies is high (Michaelowa and Jotzo, 2005; Okubo and Michaelowa, 2010; Castro and Michaelowa, 2011; Buen, 2013).

Largely due to, "[w] stimulus for small-scale, dispersed project types," carbon abatement projects under the CDM can now be implemented under the Programme of Activities (PoA) (Buen, 2013: 8). Through this modality of the CDM, activities are executed through replicable individual projects termed "Component Project Activities" (CPAs) ${ }^{2}$, with the major modification that an unlimited number of these CPAs can be bundled under one PoA for 28 years without the need to go through the registration process over and over again. The organizational and financial framework for all projects under the PoA only needs to be established and registered once by a managing entity, while baseline methodologies apply at the CPA level. An unlimited number of CPAs may then be generated for each project, reducing transaction costs for each individual project (Hinostroza et al., 2009). According to Castro and Michaelowa (2011: 126), the PoA has already started to

\footnotetext{
${ }^{1}$ The data is available from http://www.cdmpipeline.org/. Accessed on August 19, 2013. The UNEP Risoe database on CDM and Joint Implementation (JI) projects includes registered projects, projects waiting for registration, and projects at the validation stage.

2Initially, CPA stood for "CDM Programme Activity."
} 
reduce transaction costs, though progress has been slow. According to Kumar (2013), the PoA has significantly reduced transaction costs for energy efficiency projects. To contrast with the figures from the CDM above, there are six African countries among the top 20 PoA host countries, with South Africa and Kenya being ranked as second and fourth. ${ }^{3}$

In short, the PoA modality allows for the implementation of small projects that each produce few carbon credits and would otherwise have been unfeasible. Typical PoAs include rural electrification CPAs, which yield high sustainable development co-benefits but were previously unattractive as CDM projects (Matschoss, 2007). By reducing transaction costs and easing demands on institutional capacity, the PoA is intended to facilitate access to revenue from previously unprofitable carbon projects in host countries more generally, but LDCs in particular. In this sense, the PoA could help carbon abatement projects contribute to sustainable development more broadly. As many authors have emphasized, connecting the development and climate agendas promises many benefits and may even increase the legitimacy of global climate cooperation (Najam, Huq, and Sokona, 2003; Kok et al., 2008; Román, Linné, and Mickwitz, 2012).

Has the PoA made clean development more favorable to LDCs? More generally, do the determinants of PoA implementation in host countries differ from those of CDM implementation? To investigate these questions, we conduct a statistical analysis of conventional CDM projects and PoAs in the 2007-2012 period. Statistical models are useful because they allow us to isolate the effects of country size, income, and other developmental factors by controlling for other factors. Our panel dataset covers at most 85 countries, 8,815 CDM projects, and 777 PoAs. The purpose of the analysis is to test the hypothesis that PoAs are systematically implemented in different countries than CDM projects. If PoA corrects a bias against the LDCs, then PoA implementation should be less dependent on factors such as wealth compared to CDM implementation. Other determinants of project implementation. could also be different.

Are PoAs less dependent on economic size and dynamism than conventional CDM projects? We find that population is an excellent predictor of both CDM and PoA implementation. Both CDM projects and PoAs are concentrated in large countries, such as China and India. As such,

\footnotetext{
${ }^{3}$ Project counts for the African countries among the top 20 PoA hosts are as follows: South Africa (104 PoAs), Kenya (34 PoAs), Uganda (12 PoAs), Ghana (10 PoAs), Rwanda (9 PoAs), and Nigeria (8 PoAs).
} 
the PoA modality appears not to correct what some have perceived to be a bias against small countries. Per capita income has a weak positive effect on the count of CDM projects, and no effect at all on PoAs. In this regard, there seems to be some difference between the conventional CDM and PoA modalities, though the difference is not large.

The geographic distribution of PoAs could also differ from the conventional CDM with regard to some other important indicators of development. For one, we decided to investigate the relationship between urbanization and PoAs. The kinds of small and decentralized projects that the PoA promotes, such as off-grid electrification based on renewable energy, hold particular promise in rural areas (Cabraal, Barnes, and Agarwal, 2005; Brass et al., 2012). Among all the factors that could influence the implementation of PoAs, large rural populations are particularly interesting, given the potential of small carbon abatement projects for rural development. Consequently, we analyzed the relationship between urbanization and PoA implementation. We found that there is no association between the share of urban population and CDM projects or PoAs.

Another important factor we investigate is corruption. Given that PoAs are often small, their successful implementation is critically dependent on avoiding excessive transaction costs. Accordingly, we hypothesize that PoAs could prove particularly beneficial for LDCs that have made progress in their anti-corruption efforts and promotion of good governance. Normatively, this analysis is important because if our hypothesis is valid, the PoA modality may reward LDCs for good governance.

Indeed, we learned that PoAs are more sensitive to corruption than CDM projects are. An increase in corruption by one standard deviation above the mean reduces expected project counts by $49 \%$ for PoAs, but only by $30 \%$ for CDM projects. The CDM seems to favor countries that have managed to suppress corruption in government less than the PoA rewards efforts against corruption. In this sense, the PoA offers new opportunities for those LDCs who have made progress on governance in recent years.

To summarize, the findings indicate that PoAs are implemented in structurally different countries than conventional CDM projects. In particular, the PoA modality seems to hold promise for sustainable development in poor countries that have already exceeded a certain threshold of 
good governance. From a policy perspective, this is an encouraging finding. Where conventional CDM projects fail, the PoA fills an important gap in sustainable development. Moreover, the PoA rewards developing countries with competent implementing agencies and limited corruption. Although the PoA, similar to conventional CDM, seems to reward large developing countries, it holds promise for supporting sustainable development and encouraging good governance, if perhaps only on the margin.

\section{Clean Development Mechanism and the Programme of Activities}

The CDM is a system that allows firms in developing countries to invest in climate mitigation projects and sell the resulting "carbon credits" to industrialized countries that have committed to reducing their emissions under the Kyoto Protocol. One of the main criticisms of the CDM has been the severe geographic disparity in rates of CDM implementation. The CDM has disproportionately benefited certain countries, most notably China and India, as shown in Figure 1. For purposes of comparability, the two graphs show the distribution of CDM and PoAs during the 2007-2012 period, when both the CDM and PoA were active. While China, India, and Brazil still host large numbers of PoAs, the new modality does improve distribution. For example, 32\% of PoAs are implemented in Africa, as compared to 2.3\% of CDM projects.

\section{[Figure 1 about here.]}

Additionally, Table 1 shows the distribution of CDM projects and PoAs over time as implemented in LDCs and non-LDCs. ${ }^{4}$ The patterns show that the PoA is much more beneficial to LDCs than conventional CDM projects. While LDCs only account for about 1\% of CDM projects in the years 2007-2012, about $12 \%$ of PoAs can be found in least developed countries in most of the years, ignoring 2007 where only 2 PoAs were submitted for validation.

[Table 1 about here.]

The unequal distribution of the CDM has largely been attributed to both the challenging requirements of the formal CDM project cycle and the unconventional combination of country char-

\footnotetext{
${ }^{4}$ In categorizing countries, we follow the official UN classification, available online from http://www. unohrlls. org/en/ldc/25/. Accessed on October 30, 2013.
} 
acteristics needed to attract investment in CDM projects (Greene, 2005; Castro and Michaelowa, 2011). The rigorous seven-step CDM project cycle requires high institutional capacity and the financial means to overcome transaction costs associated with formal project registration. Each country that hopes to host a CDM project must first create additional institutions to ensure compliance with the CDM regulations. For this, a Designated National Authority needs to be created to give national approval that host country participation in the proposed CDM projects is voluntary and that the projects foster sustainable development. In addition, Designated Operational Entities need to evaluate CDM projects prior to registration with the scheme and before carbon credits can be issued. This is to ensure that project activities comply with the regulations and requirements of the CDM and facilitate emissions reductions. For the project developer, the entire process requires a Project Design Document, which demands a detailed discussion of the applied methodologies and thorough evidence of the project's additionality and effectiveness in carbon abatement. Without complying with this formalized project cycle, carbon credits will not be issued by the CDM's Executive Board (UNFCCC, 2012). ${ }^{5}$ These steps require technical expertise, legal capacity, and time before revenues from Certified Emission Reduction (CER) carbon credits can be generated. The administrative costs associated with the project cycle may be sizeable and impede project registration, especially for small projects (Michaelowa and Jotzo, 2005).

The attractiveness of a country or region as project host depends on its marginal abatement cost of emissions reductions, its institutional capacity, and business climate for investors (Castro and Michaelowa, 2011; Winkelman and Moore, 2011; Dinar et al., 2011; Castro, 2012; Jung, 2006; Oleschak and Springer, 2007). While developing countries often have more low-cost mitigation potential than industrialized countries due to inefficiencies in the energy sector, they are also more likely to have less regulatory certainty, more economic and political instability, and lower institutional capacity than industrialized countries (Oleschak and Springer, 2007). Therefore, we would expect to see CDM projects in host countries with both high mitigation potential, which is typically associated with underdevelopment, and strong institutions specific to the demands of the CDM. China and India are notable examples in that they both possess comparatively

\footnotetext{
${ }^{5}$ Further details on the CDM project cycle can be found at http://cdm. unfccc.int/Projects/diagram.html. Accessed on December 31, 2011.
} 
low marginal abatement costs, strong enough institutions to support the CDM, and a reliable investment climate (Jung, 2006; Ganapati and Liu, 2009). At the same time, the CDM rules were never designed to strongly support re- and afforestation projects (Ellis and Kamel, 2007).

In view of these barriers to CDM project implementation in least developed countries, the PoA was intentionally designed to support the implementation of small projects (Buen, 2013). The PoA cycle is similar to that for CDM projects, but with several useful modifications. The most important feature is the possibility that, once a PoA is registered, an unlimited number of individual replicable component activities can be added under the same PoA without undergoing any additional registration procedures. Moreover, the PoA lifetime is 28 years, instead of the conventional 21 years. Instead of registering projects on a case-by-case basis, it is sufficient to register one generic project, bypassing the need to specify each individual activity (Hinostroza et al., 2009). This is particularly important because many PoAs have, due to their small scale and dispersed nature, relatively higher transaction costs than conventional CDM projects. In this regard, the option to add replicable component activities is particularly important.

The PoA also affects the types of projects which are carried out under the CDM. Absent the PoA scheme, the high transaction costs of registering a project limit CDM activities to large projects, such as large hydroelectric dams, which generate a sufficient amount of carbon credits to justify the procedural cost (Michaelowa and Jotzo, 2005; Schatz, 2008). In contrast, the PoA offers to implement multiple projects that are each smaller in scale and geographically more dispersed. As climate mitigation projects, which often come with technologies that support sustainable development in rural areas, may benefit the most from bundling projects under the PoA (Winkelman and Moore, 2011) successful implementation of PoAs may ultimately enhance chances of sustainable development.

To assess this claim, we need to understand what determines PoA implementation, particularly in comparison to conventional CDM projects. We examine population size, per capita income, the share of urban population, and corruption levels as predictors of worldwide CDM and PoA distribution. Of these, population size and per capita income capture the idea that the PoA may, or may not, be more favorable to small and poor countries than the CDM is. These 
two variables are critical to understanding the PoA's ability to correct what some consider a bias in favor of larger and more developed countries under the CDM.

The focus on urbanization is warranted because the small and dispersed projects that the PoA promotes, such as off-grid electrification schemes based on renewable energy, are particularly suited for promoting sustainable rural development. Therefore, it is important to scrutinize if PoAs have guided carbon abatement projects toward societies whose large rural populations may expect significant benefits from projects. In a similar way, corruption is an interesting explanatory variable because PoAs are, due to their small size, critically dependent on avoiding the unnecessary transaction costs that corruption may bring. Furthermore, if low corruption levels promote PoAs, then the PoA modality rewards developing countries for good governance. Since the literature on the CDM emphasizes many other explanatory factors, it is not necessary for us to consider a more extensive array of variables. Of course, we control for them in the regressions.

\subsection{Population}

To establish a baseline for CDM and PoAs, we consider a country's population. All else constant, large populations create more opportunities for carbon abatement (Flues, 2010). Large countries should implement more CDM and PoAs than small countries. This effect should apply to both modalities because large countries simply have more abatement opportunities, regardless of the modality. As a baseline, we thus expect large countries to implement more CDM projects and PoAs, so that the PoA would not promote the interests of small developing countries in particular.

CDM Hypothesis 1 (population and CDM projects). All else constant, countries with larger populations implement more CDM projects than countries with smaller populations.

PoA Hypothesis 1 (population and PoAs). All else constant, countries with larger populations implement more PoAs than countries with smaller populations.

\subsection{Per Capita Income}

If the PoA does effectively correct the bias of the CDM against least developed countries, we would expect the implementation of PoAs to be less dependent on wealth. Previous research has found that the CDM systematically favors wealthier developing countries (Flues, 2010), which 
means that the LDC group is at a disadvantage. Since the PoA reduces fixed transaction costs for small projects, rendering them feasible, this modality should facilitate the implementation of projects in the poorest nations. The possibility of combining small projects facilitates implementation in countries that do not have enough capital to initiate large projects. Projects may also be implemented in stages, building to larger energy projects that would be impossible to implement at once when capital is scarce (Climate Focus, 2011).

Another obstacle mitigated by the PoA pertains to the prevailing trend of unilateral project implementation under the CDM. While the CDM was initially envisioned as a bilateral or multilateral instrument, unilateral projects without the direct support from a foreign project partner have become attractive (Michaelowa, 2007; Lütken and Michaelowa, 2008). LDCs have often not been able to implement unilateral CDM projects because they lack the capacity to do so (Flues, 2010). As PoAs are supposed to be more clearly geared toward sustainable development than CDM projects, the PoA may encourage investment by multilateral and bilateral donor agencies. Given these arguments, we expect that while CDM project implementation should increase with per capita income, economic wealth should not affect patterns of PoA implementation. If the hypothesis fails, then the PoA is not correcting the bias against the more advanced developing countries.

CDM Hypothesis 2 (per capita income and CDM projects). All else constant, countries with higher per capita incomes implement more CDM projects than countries with lower per capita incomes.

PoA Hypothesis 2 (per capita income and PoAs). The number of PoAs that a country implements depends less on per capita income than the number of CDM projects implemented.

\subsection{Rural Energy Development}

As already mentioned above, the CDM and the PoA modalities differ in terms of the project types that they attract. PoAs are comparatively small in size and better suited to be used in widely dispersed rural environments. For the successful implementation of CDM projects, however, economies of scale matter to a larger extent. Michaelowa and Jotzo (2005) as well as Schatz (2008) show that initially, most CDM projects were focused on the destruction of chemicals that 
are potent greenhouse gases or the construction of large renewable energy facilities. Today, the $\mathrm{CDM} / \mathrm{JI}$ Pipeline data indicate the importance of renewable electricity generation from wind and hydroelectric sources. ${ }^{6}$ The contrast to the PoA is remarkable. For example, only $2.7 \%$ of all CDM projects implemented by December 31, 2012, promoted solar energy, compared to $16.9 \%$ under the PoA; given that solar energy is particularly suitable for rural applications as a decentralized electricity solution, PoAs seem to promote electricity generation that can be easily decentralized. Similarly, the PoA has implemented projects that promote efficient cook stoves and improved household lighting through improved technologies. These issues are particularly important in rural areas, and they cover the vast majority of PoAs focused on household energy efficiency; moreover, $22.1 \%$ of PoAs fall under this category, compared to only $1.1 \%$ of CDM projects.

Based on this reasoning, we expect to find a negative relationship between the levels of urban population and PoA implementation. Countries with largely urban populations should be less likely to host PoAs, while we do not expect any relationship between the size of urban populations and CDM project allocation. On the one hand, urbanization could encourage CDM implementation because of higher emissions potential among the wealthy urban middle class. On the other hand, a large rural population encourages the kinds of rural projects discussed above. Moreover, urbanization may increase the efficiency of transportation and power generation due to high population densities.

CDM Hypothesis 3 (urbanization and CDM projects). The number of CDM projects that a country implements does not depend on the degree of urbanization.

PoA Hypothesis 3 (urbanization and PoAs). All else constant, countries with lower urbanization levels will implement more PoAs than countries with higher urbanization levels.

\subsection{Corruption}

PoAs are smaller in size and may therefore be more sensitive to corruption and lack of good governance. With burgeoning levels of corruption, transaction costs increase while revenue streams for project developers decrease. If corruption levels are high and rent extraction is considerable,

\footnotetext{
${ }^{6}$ See http://www. cdmpipeline.org/. Accessed on August 19, 2013.
} 
PoAs which anyways hold rather small monetary benefits may soon be no longer profitable. Therefore, PoA developers who operate with small profit margins are likely to be more sensitive to high levels of corruption than CDM project developers. Large CDM projects not only produce disproportionately larger amounts of carbon credits, but are also more resilient to revenue losses caused by corrupt officials. The larger the size of the project, the less important fixed costs and one-off bribes are. This suggests that we should see only a moderate effect of corruption levels on patterns of CDM project implementation, whereas higher corruption levels can be expected to disincentivize project implementation strongly in the case of PoAs.

CDM Hypothesis 4 (corruption and CDM projects). The number of CDM projects that a country implements depends only weakly on corruption in governmental institutions.

PoA Hypothesis 4 (corruption and PoAs). All else constant, countries with higher corruption levels implement fewer PoAs than countries with lower corruption levels.

To be sure, it is important to remember that large projects may be more lucrative as targets of rent extraction for corrupt officials. If this is the case, then the CDM could also suffer from corruption, as project developers anticipate demands for bribes. Consequently, the CDM-PoA difference in the effect of corruption could be smaller than we initially anticipated.

\section{Research Design}

To examine the effects of country size, per capita income, share of urban population, and corruption on CDM projects and PoAs, we used data from the CDM/JI Pipeline Database. ${ }^{7}$ The unit of analysis is a country-year, and the dependent variable is a count of normal CDM projects or PoAs, as reported in the CDM Pipeline, with projects waiting for registration, registered, or at the validation stage. ${ }^{8}$ Given that the PoA is only seven years old and most projects are recent, it is important to include projects that have yet to be registered. Otherwise, we could not draw lessons from the statistical data. Indeed, there were only 395 projects registered under the PoA by the end of 2012. Since both CDM projects and PoAs were implemented during the 2007-2012

\footnotetext{
${ }^{7}$ See http://www. cdmpipeline.org/. Accessed on August 19, 2013.

${ }^{8}$ Rejected and withdrawn projects are, therefore, excluded.
} 
period, we focus on this time period. Including CDM projects before 2007 would bias the comparisons between the CDM and the PoA, given that we would be comparing two different sets of country-years. At the same time, we do recognize that the standard CDM had accumulated experience during the years 2003-2006, and this head start may influence the CDM-PoA difference. ${ }^{9}$ Our models have at most 85 non-OECD countries and 482 observations, depending on data availability.

\subsection{Dependent Variables}

Our first dependent variable is a count of CDM projects submitted for validation in a country in a given year. The second dependent variable is a similar count of PoAs. We focus on project counts, instead of expected emissions reductions, because the size of CDM projects and PoAs differs.

\subsection{Independent Variables}

Our first two independent variables are population of a country and per capita income, measured in constant 2005 United States dollars. We logarithmized both variables to avoid bias from nonnormal distribution. Data for both variables is taken from the World Development Indicators (WDI).

Our third independent variable is the share of urban population, measured as the percentage of people living in urban areas relative to total population. The data comes again from the WDI.

Finally, we include a measure of corruption from Transparency International's Corruption Perceptions Index. ${ }^{10}$ This index focuses on the public sector and is based on surveys and assessments by various international organizations. We invert the raw data so that high values indicate more corruption. In our data, the variable ranges from 0.6 to 9.00. All independent variables are lagged by three years due to missing data and to avoid simultaneity bias.

\subsection{Control Variables}

We include several control variables in different models. Given the relatively small number of observations, we cannot include all of them in one model; the models simply do not converge if we

\footnotetext{
${ }^{9}$ In the online appendix, we show that we obtain similar results for conventional CDM projects if we extend the time period covered to years 2003-2012. To be able to better compare CDM projects and PoAs, we prefer the 2007-2012 period.

${ }^{10}$ See http://www.transparency.org/research/cpi/overview. Accessed August 22, 2013.
} 
include random effects to account for unobservable heterogeneity across countries. Instead, we estimate models with various combinations of control variables. All control variables are lagged by three years to avoid simultaneity bias and to keep them consistent with our independent variables.

In one model, we include the one-year lag of the dependent variable to account for path dependence. A country's propensity to implement CDM projects at one point in time could depend on previous experience through learning and scale effects. According to Winkelman and Moore (2011), previous project implementation predicts the emergence of new projects. For this, we also include lagged CDM and PoA counts, respectively, to examine whether CDM project count influences PoA implementation, and vice versa.

To account for institutional factors, another model contains a binary indicator for democracy, measured as the existence of free and competitive elections (Cheibub, Gandhi, and Vreeland, 2010). Since CDM projects and PoAs may promote sustainable development, democratic rulers, whose political survival depends on supplying public goods (Lake and Baum, 2001), may have stronger incentives to support such projects through conducive regulations and policies.

Since some CDM projects feature foreign partners, we also include the country's attractiveness as a host of foreign investment (Ellis and Kamel, 2007; Flues, 2010). If a country is generally a good environment for foreign investors, then it should be more able to implement projects that require collaboration with foreign companies. For this, we use the "Government Stability" variable from the International Country Risk Guide. ${ }^{11}$

To control for environmental and resource efficiency considerations, one model includes a measure of energy intensity, carbon dioxide intensity, and urban concentrations of suspended particulate matter (PM10). Since the CDM is intended to support projects that promise inexpensive carbon abatement opportunities, high energy or carbon dioxide intensity might encourage project development. The PM10 measure, on the other hand, reflects the possible local benefits of climate mitigation in the cities. Since one of our hypothesis focuses on urbanization, this control is important. The data for the three variables are from the WDI.

\footnotetext{
${ }^{11}$ See http://www.prsgroup.com/ICRG_methodology. aspx for methodological details. Accessed December 3, 2012.
} 
Since the characteristics of the electricity sector may influence CDM and PoA implementation (Flues, 2010), another model includes controls for transmission and distribution losses in percentage, as well as the share of coal in domestic electricity generation relative to total generation. Inefficiency in the electricity sector and reliance on carbon-intensive coal could create opportunities for project implementation. These data are also from the WDI.

To control for economic structure, we include the logarithmized value of trade flows, measured as percentage of GDP, the share of industrial production relative to annual GDP, and domestic savings as a percentage of GDP. Of the three, trade flows also capture relationships between sellers and buyers of CDM carbon credits (Wang and Firestone, 2010; Dinar et al., 2011). Industrial production favors certain types of projects that may not be favorable under the PoA modality, such as the installation of energy saving devices in factories. The domestic savings rate captures capital formation, which encourages investment. Again, the data are from the WDI.

Finally, to consider demographic characteristics other than total population, our last model controls for population density, measured as people per square kilometer of territory. This variable captures resource availability per capita, which could encourage project implementation due to a low resource efficiency. We also add life expectancy at birth to this specification to account for social development, which could be particularly important for the PoA. Again, data come from the WDI.

All models include year fixed effects, while model (2) also includes region fixed effects. For this, we add regional dummies for Asia, Africa, the Americas, and Europe, while using Oceania as baseline category, which consistently hosts the lowest number of CDM projects and PoAs.

\subsection{Statistical Model}

We estimate negative binomial count models, with random effects by country. Because we have at most seven years per country, we cannot estimate models with country fixed effects. In the supplementary appendix, we report estimation results from zero-inflation models with lagged $\mathrm{CDM}$ and PoA counts, respectively, as well as a linear time trend as regressors at the inflation stage. As zero-inflated and negative binomial models allow for the same substantive conclusions, while zero-inflation comes with the cost of estimation instability, we prefer the simpler negative 
binomial models. This choice is innocuous as estimated coefficients from both model types are virtually identical, both in terms of coefficients' signature and level of statistical significance. Likelihood ratio tests suggest that negative binomial models outperform Poisson count models because the equidispersion assumption fails.

\section{Results}

We begin with a summary of our main findings. Given that our count models are nonlinear, we also simulate substantive effects and offer a graphical summary. Then, we briefly summarize our robustness checks.

\subsection{Main Findings}

The main results for CDM projects are reported in Table 2. Each model contains the population, income, urban population, and corruption variables. Model (2) includes region fixed effects. For models (3)-(8), the other control variables are included in substantively meaningful groups. As the table shows, population is a strong and consistent predictor of CDM activity. The coefficient for income is also positive, though the size of the coefficient varies and loses statistical significance in several models. Urban population share has no effects on CDM project activity, while corruption does. These findings are broadly consistent with our hypotheses. First and foremost, the CDM is a system that allows large economies to implement carbon abatement projects; to a lesser extent, income also appears to be important. Perhaps the most important deviation from our expectations is that corruption does appear quite important. As shown below, though, it is much more important for the PoAs.

[Table 2 about here.]

As for the control variables, the most notable findings are the positive effect of democracy and the negative effect of population density. This suggests that CDM projects are concentrated in countries that allow people to influence their lives through the political system and have abundant resources. Urban concentrations of particulate matter are negatively associated with project implementation. It is initially surprising that energy and carbon intensity, the share of 
coal in electricity generation, and the share of industry in total GDP have negative coefficients. The effects are not statistically significant, however, so the true coefficient could well be zero.

In Table 3, we analyze the same set of models but use the PoA count as the dependent variable. For the population variable, the results are similar. The positive population effect is consistent across the models. However, per capita income does not seem to predict increased PoA activity. Contrary to our hypothesis, urbanization appears irrelevant. The corruption variable is negative and statistically significant in all models. As to control variables, only energy intensity is statistically significant. Interestingly, countries with high energy intensities seem to implement fewer projects. This could reflect the additionality requirement, whereby neither the CDM nor the PoA support projects that are commercially viable, perhaps due to wasteful energy consumption in the first place.

[Table 3 about here.]

The substantive effects based on simulations (King, Tomz, and Wittenberg, 2000) are shown in Figure 2. The estimates are ratios of expected project counts as we move from the mean of each variable to one standard deviation above it. Values above unity indicate a positive effect; values below it indicate a negative effect. We drew 1,000 values from a multivariate normal distribution based on the basic model (1) without controls in Tables 2 and 3. The error bars indicate 95\% confidence intervals.

[Figure 2 about here.]

As expected, population has a positive effect on both CDM projects and PoA. An increase of one standard deviation above the mean increases the number of CDM projects and PoAs by factors of 2.06 and 2.84, respectively. Both effects are statistically significant. Income also has a positive and statistically significant effect for CDM projects, but not for PoAs. An increase of one standard deviation above the mean causes a positive change by a factor of 1.71 for CDM projects. On the contrary, for PoAs the mean effect, albeit not statistically significant, is even negative, with PoA counts reducing by about 7\% points when income is increased by one standard deviation. 
This strongly speaks to the asymmetry of which determinants are key to explaining CDM project and PoA counts.

As for urbanization, the effects are statistically insignificant for both the CDM and PoA. While the mean effect is positive for CDM projects with an average increase of CDM project counts by a factor of 1.27 (0.70 and 2.14 as lower and upper confidence bounds), the mean effect prompted for PoAs is negative, with a mean decrease in PoA activity by a factor of 0.86 (0.56 and 1.32 as lower and upper confidence bounds).

Higher levels of corruption have large negative effects for project implementation, independent of the modality. Increasing corruption levels from a mean value of 6.77 by $21 \%$ reduces CDM project counts by $30 \%$, while PoA counts drop more substantially, by even $49 \%$. This suggests that the average effect of corruption is almost twice as strong for PoAs compared to CDM projects. Together, these findings indicate that PoAs are concentrated in countries with large populations and at least somewhat competent and non-corrupt public agencies.

To summarize, a key difference between CDM projects and PoAs lies in governance. Good governance in the form of low corruption levels appears necessary for reducing transaction costs. There is also a less notable difference in the effect of income per capita, as poor countries seem not to be penalized by the PoA.

\subsection{Robustness}

The supplementary appendix presents various additional tests. If we exclude each year from our sample one-by-one, our results generally hold. This finding is important as our results seem not to be affected by regulatory uncertainty of the PoA during the early years and 2007 in particular. Moreover, the CDM results are unchanged if we also include the years 2003-2006. If we exclude each region one-by-one, our results are relatively robust, even though statistical significance for the income variable decreases for CDM projects when we exclude projects from Africa and the Americas; given the sizable amount of projects implemented in these regions, this loss in statistical significance is not too surprising.

To consider outliers, we also implemented models that exclude the largest host countries oneby-one. Specifically, for the CDM, we excluded projects from China (4,070 projects, or 46.1\%), 
India (2,373 projects, or 26.9\%), Brazil (449 projects, or 5.1\%), Malaysia (218 projects, or 2.5\%), and Thailand (210 projects, or 2.4\%). For the PoA, we excluded China (124 PoAs, or 15.9\%), South Africa (104 PoAs, or 13.4\%), India (85 PoAs, or 10.09\%), Kenya (34 PoAs, or 4.4\%), and Indonesia (33 PoAs, or 4.2\%). Our results continue to hold.

We also considered the possibility that foreign aid is driving the spread of PoAs. We used official development aid data from the WDI, both on a per capita basis and relative to GDP. While we find strong evidence in the PoA sample that foreign aid encourages PoA allocation, our main findings remain intact. In comparison to conventional CDM projects, no such effect of foreign aid can be found.

Finally, we re-estimate our models for the CDM sample considering only small CDM projects, which account for about $41 \%$ of the projects in our sample. As PoAs are generally smaller than CDM projects, this is a reasonable test for the importance of project size. For this, we classified CDM projects as "small" if they used one of the small scale methodologies, approved by the UNFCCC. ${ }^{12}$ Interestingly, we find exactly the same pattern in the data as with the full sample, when using all CDM projects. This is remarkable as especially the income effect remains positive and statistically significant for small CDM projects, suggesting that the non-effect of the income variable for PoAs is not driven by project size, but rather by the differences in the design of the two modalities. This reinforces the interpretation that the PoA, by its very design, does alleviate potential biases against the LDCs that are prevalent under CDM regulations.

\section{Conclusion}

While the CDM is an important channel through which the Kyoto Protocol promotes climate mitigation in developing countries, the criteria for project implementation have created a bias against small projects in the least developed countries. The PoA is a modality intended to facilitate the implementation of small projects with considerable potential for sustainable development. Has it made progress toward this goal so far? Our statistical analysis of CDM projects and PoAs in the universe of host countries, 2007-2012, offers the answer of a qualified yes. While population

\footnotetext{
${ }^{12}$ See http://cdm.unfccc.int/methodologies/SSCmethodologies/approved for a complete list of all approved small scale methodologies. Accessed on April 4, 2013.
} 
size is the main determinant of project implementation for CDM projects and PoAs, per capita income has a weak positive effect only on the CDM. At the same time, low levels of corruption have attracted investment in climate mitigation under the PoA modality in particular.

More scholarship is required on the topic to improve the design of flexibility mechanisms in service of clean development. Our analysis is ultimately based on a relatively small sample of PoAs, as this modality remains young. Over time, new experience with PoA implementation could qualify some of our conclusions. We hope, however, that our initial results encourage more scholars to study the CDM and the PoA from a comparative perspective.

Future research could include case studies and interviews conducted with project managers to assess what characteristics in particular attracted their investment. While space constraints prevented us from doing this, the quantitative estimations offer several hypotheses on factors that could play a key role in PoA implementation and distinguish it from conventional CDM. Similarly, the findings offer ideas for how to evaluate the sustainable development contribution of the PoA. Our evidence suggests, for instance, that the PoA holds promise for sustainable development. Since the CDM's Executive Board adopted a tool for describing and evaluating CDM project co-benefits at the 2012 COP in Doha, Qatar, this trend toward sustainable development broadly defined may grow stronger in the CDM's future. ${ }^{13}$

For the proponents of the CDM, the news is welcome. While the CDM has arguably reduced carbon dioxide emissions, its contribution to sustainable development remains a controversial proposition (Crowe, 2013). We have shown that the PoA has, at the very least, started to address this issue. If the PoA continues to serve poor populations in those least developed countries that have exceeded a certain threshold of good governance, it could make an important contribution to sustainable rural development. In a world of rapid population growth and resource consumption, enhancing development in an environmentally sustainable fashion could mitigate the pressure on natural resources. If the international community scaled up the PoA, they could use it to pursue their environmental and developmental goals.

\footnotetext{
${ }^{13}$ See “CDM Executive Board Adopts Tool to Promote Sustainable Development Co-Benefits." Available at http:// climate-l.iisd.org/news/cdm-executive-board-adopts-tool-to-promote-sustainable-development-co-benefits/. Accessed on March 29, 2013.
} 


\section{References}

Brass, Jennifer N., Sanya Carley, Lauren M. MacLean, and Elizabeth Baldwin. 2012. "Power for Development: A Review of Distributed Generation Projects in the Developing World." Annual Review of Environment and Resources 37: 107-136.

Buen, Jørund. 2013. "CDM Criticisms: Don't Throw the Baby out with the Bathwater." FNI Climate Policy Perspectives 8.

Cabraal, Anil R., Douglas F. Barnes, and Sachin G. Agarwal. 2005. "Productive Uses of Energy for Rural Development." Annual Review of Environment and Resources 30: 117-144.

Castro, Paula. 2012. "Does the CDM Discourage Emission Reduction Targets in Advanced Developing Countries?" Climate Policy 12 (2): 198-218.

Castro, Paula, and Axel Michaelowa. 2011. "Would Preferential Access Measures Be Sufficient to Overcome Current Barriers to CDM Projects in Least Developed Countries?" Climate and Development 3 (2): 123-142.

Cheibub, José Antonio, Jennifer Gandhi, and James Raymond Vreeland. 2010. "Democracy and Dictatorship Revisited." Public Choice 143 (1-2): 67-101.

Climate Focus. 2011. “The Handbook for Programme of Activities: Practical Guidance to Successful Implementation." www.cd4cdm.org/Publications/Handbook_Implementation_PoA.pdf.

Crowe, Tracey L. 2013. "The Potential of the CDM to Deliver Pro-Poor Benefits." Climate Policy 13 (1): 58-79.

Dinar, Ariel, Shaikh Mahfuzur Rahman, Donald F. Larson, and Philippe Ambrosi. 2011. "Local Actions, Global Impacts: International Cooperation and the CDM." Global Environmental Politics 11 (4): 108-133.

Ellis, Jane, and Sami Kamel. 2007. "Overcoming Barriers to Clean Development Mechanism Projects." OECD, IEA, and UNEP Risoe Centre.

Flues, Florens. 2010. "Who Hosts the Clean Development Mechanism? Determinants of CDM Project Distribution." CIS Working Paper 53.

Ganapati, Sukumar, and Liguang Liu. 2009. "Sustainable Development in the Clean Development Mechanism: The Role of Designated National Authority in China and India." Climate Policy 52 (1): 43-60.

Greene, William. 2005. "The Clean Development Mechanism in Sub-Saharan Africa: Left Out but not Left Behind." In The Finance of Climate Change: A Guide for Governments, Corporations and Investors, ed. Kenny Tang. London: Riskbooks pp. 353-366.

Hinostroza, Miriam, Alfredo D. Lescano, Jorge M. Alvarez, and Francisco M. Avendano. 2009. "Primer on CDM Programme of Activities." UNEP Project 'CD4CDM'.

Jung, Martina. 2006. "Host Country Attractiveness for CDM Non-Sink Projects." Energy Policy 34: 2173-2184. 
King, Gary, Michael Tomz, and Jason Wittenberg. 2000. "Making the Most of Statistical Analyses: Improving Interpretation and Presentation." American Journal of Political Science 44 (2): 341-355.

Kok, Marcel, Bert Metz, Jan Verhagen, and Sascha van Rooijen. 2008. "Integrating Development and Climate Policies: National and International Benefits." Climate Policy 8 (2): 103-118.

Kumar, Saurabh. 2013. "Global Experience with Energy Efficiency and the Role of the Private Sector." Wiley Interdisciplinary Reviews: Energy and Environment 2 (3): 269-281.

Lake, David A., and Matthew A. Baum. 2001. "The Invisible Hand of Democracy: Political Control and the Provision of Public Services." Comparative Political Studies 34 (6): 587-621.

Lütken, Søren Ender, and Axel Michaelowa. 2008. Corporate Strategies and the Clean Development Mechanism: Developing Country Financing for Developed Country Commitments? Northampton: Edward Elgar.

Matschoss, Patrick. 2007. "The Programmatic Approach to CDM: Benefits for Energy Efficiency Projects." Carbon and Climate Law Review 2: 119-128.

Michaelowa, Axel. 2007. “Unilateral CDM: Can Developing Countries Finance Generation of Greenhouse Gas Emission Credits on Their Own?" International Environmental Agreements 7 (1): 17-34.

Michaelowa, Axel, and Frank Jotzo. 2005. "Transaction Costs, Institutional Rigidities and the Size of the Clean Development Mechanism." Energy Policy 33 (4): 511-523.

Najam, Adil, Saleemul Huq, and Youba Sokona. 2003. "Climate Negotiations Beyond Kyoto: Developing Countries Concerns and Interests." Climate Policy 3 (2): 221-231.

Okubo, Yuri, and Axel Michaelowa. 2010. "Effectiveness of Subsidies for the Clean Development Mechanism: Past Experiences with Capacity Building in Africa and LDCs." Climate and Development 2 (1): 30-49.

Oleschak, Robert, and Urs Springer. 2007. "Measuring Host Country Risk in CDM and JI Projects: A Composite Indicator." Climate Policy 7 (6): 470-87.

Román, Mikael, Björn-Ola Linné, and Per Mickwitz. 2012. "Development Policies as a Vehicle for Addressing Climate Change." Climate and Development 4 (3): 251-260.

Schatz, A. 2008. "Discounting the Clean Development Mechanism." Georgetown International Environmental Law Review 20: 703-737.

UNFCCC. 2012. “Clean Development Mechanism Project Cycle Procedure.” United Nations Framework Convention on Climate Change.

Wang, Haifeng, and Jeremy Firestone. 2010. "The Analysis of Country-to-Country CDM Permit Trading Using the Gravity Model in International Trade." Energy fo Sustainable Development 14 (1): 6-13.

Winkelman, Andrew G., and Michael R. Moore. 2011. "Explaining the Differential Distribution of the Clean Development Mechanism Projects Across Host Countries." Energy Policy 39 (3): 1132-1143. 

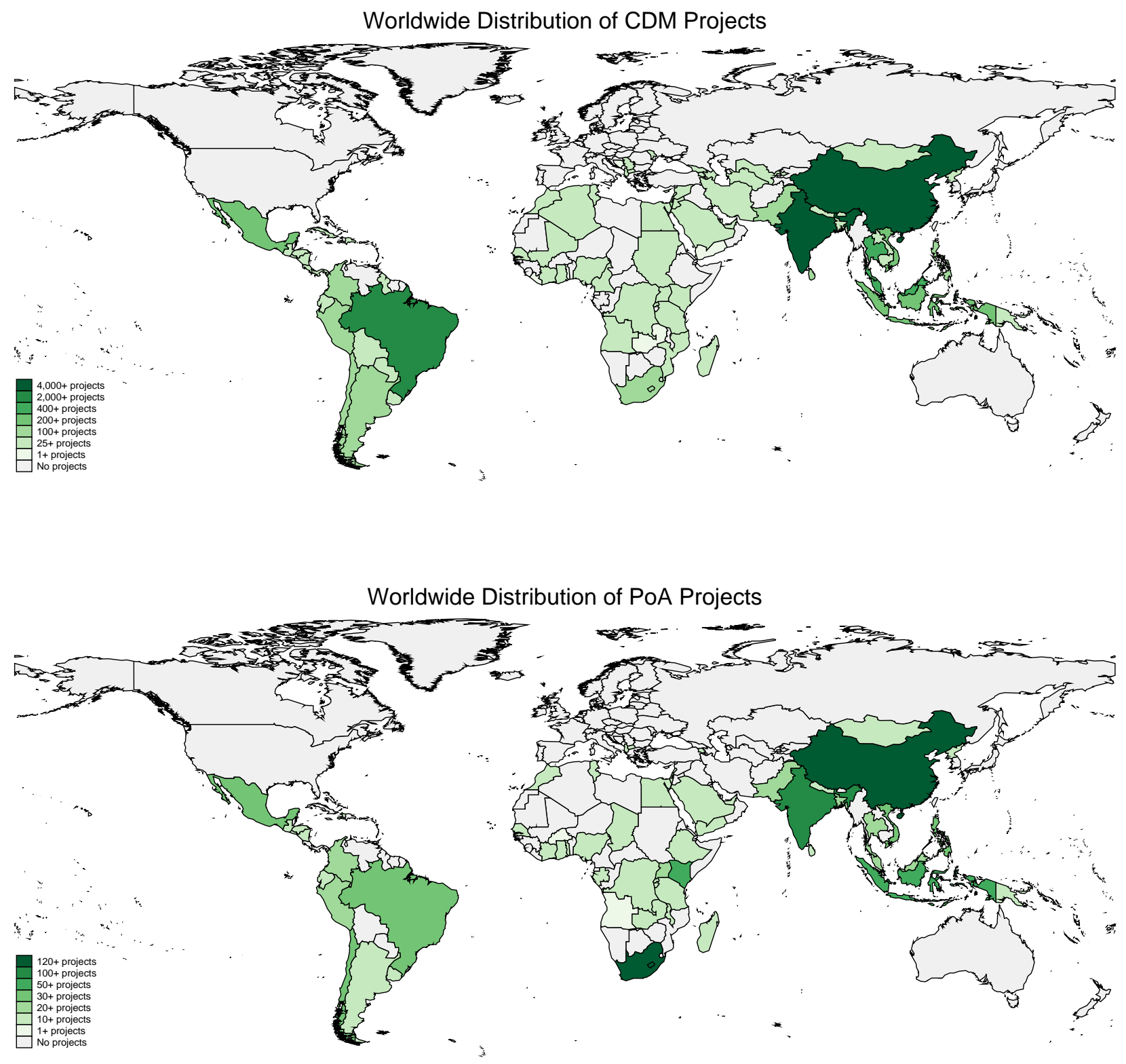

Figure 1: Worldwide distribution of standard CDM projects and PoAs, 2007-2012 (CDM/JI Pipeline Database). 


\section{Expected Ratios for CDM and PoA Project Counts}

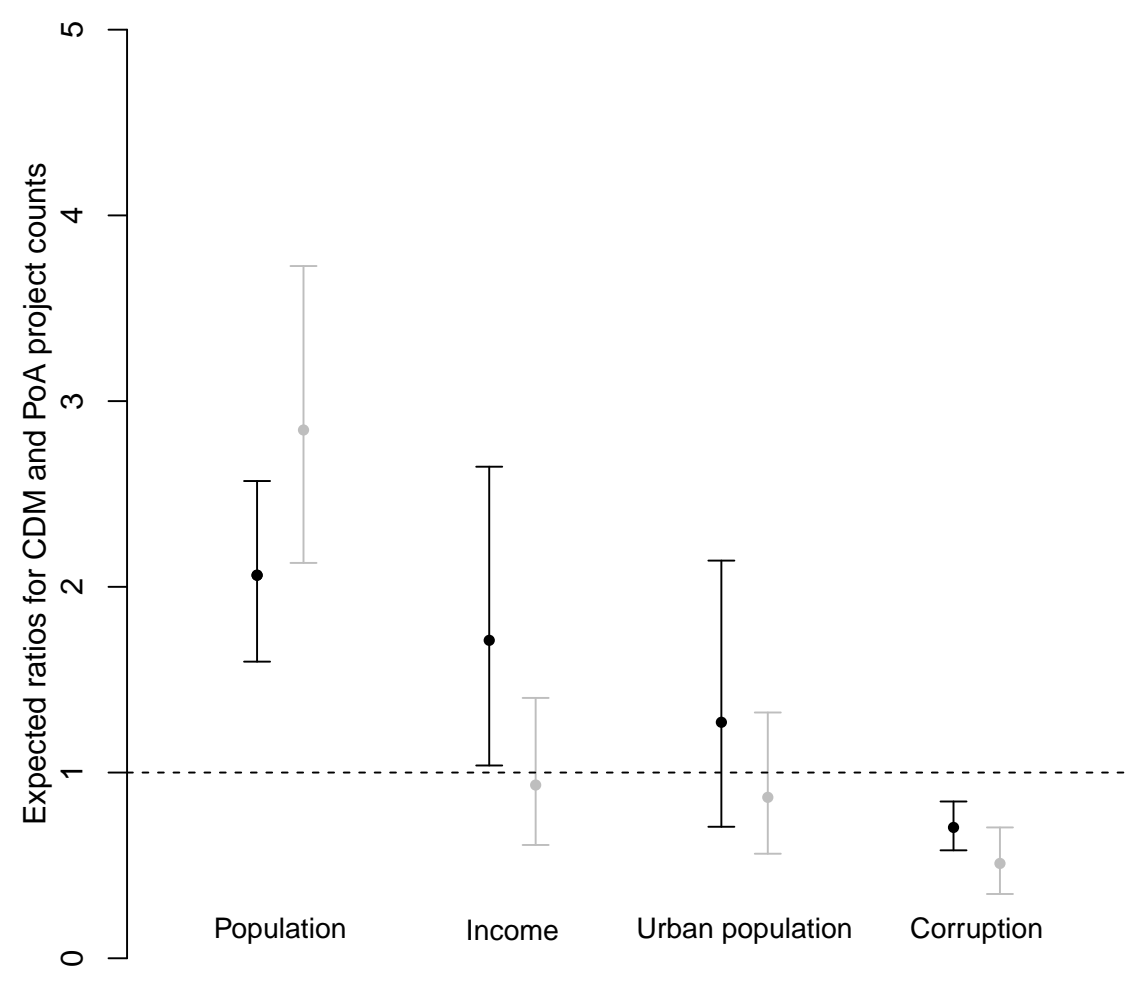

Figure 2: Substantive effects for CDM projects and PoAs. We simulated substantive effects for CDM projects (black lines) and PoAs (grey lines) for changes from the mean to one standard deviation above for four variables: population, income, urban population, and corruption. Substantive effects come from 1,000 draws from a multivariate normal distribution and are based on Models (1) in Tables 2 and 3. The error bars indicate 95\% confidence intervals. 
Distribution of CDM projects and PoAs

\begin{tabular}{|c|c|c|c|c|c|c|}
\hline & 2007 & 2008 & 2009 & 2010 & 2011 & 2012 \\
\hline \multicolumn{7}{|l|}{ PoAs } \\
\hline LDCs & $100 \%$ & $40.0 \%$ & $12.9 \%$ & $6.5 \%$ & $12.3 \%$ & $12.1 \%$ \\
\hline non-LDCs & $0 \%$ & $60.0 \%$ & $87.1 \%$ & $93.5 \%$ & $87.7 \%$ & $87.9 \%$ \\
\hline \multicolumn{7}{|c|}{ CDM projects } \\
\hline LDCs & $0.08 \%$ & $1.0 \%$ & $0.07 \%$ & $0.06 \%$ & $1.4 \%$ & $1.2 \%$ \\
\hline non-LDCs & $99.2 \%$ & $99.0 \%$ & $99.3 \%$ & $99.4 \%$ & $98.6 \%$ & $98.8 \%$ \\
\hline
\end{tabular}

Table 1: Distribution of standard CDM projects and PoAs, separately for LDCs and non-LDCs in years 2007-2012 (CDM/JI Pipeline Database). 
Main results for CDM projects

\begin{tabular}{|c|c|c|c|c|c|c|c|c|}
\hline & $\begin{array}{c}(1) \\
\text { Model }\end{array}$ & $\begin{array}{c}(2) \\
\text { Model }\end{array}$ & $\begin{array}{c}(3) \\
\text { Model }\end{array}$ & $\begin{array}{c}(4) \\
\text { Model }\end{array}$ & $\begin{array}{c}(5) \\
\text { Model }\end{array}$ & $\begin{array}{c}(6) \\
\text { Model }\end{array}$ & $\begin{array}{c}(7) \\
\text { Model }\end{array}$ & $\begin{array}{c}(8) \\
\text { Model }\end{array}$ \\
\hline Population (logged, 3yr lag) & $\begin{array}{c}0.558^{* * *} \\
(0.095)\end{array}$ & $\begin{array}{c}0.624^{* * *} \\
(0.093)\end{array}$ & $\begin{array}{c}0.604^{* * *} \\
(0.098)\end{array}$ & $\begin{array}{c}0.665^{* * *} \\
(0.099)\end{array}$ & $\begin{array}{c}0.604^{* * *} \\
(0.099)\end{array}$ & $\begin{array}{c}0.621^{* * *} \\
(0.120)\end{array}$ & $\begin{array}{c}0.568^{* * *} \\
(0.102)\end{array}$ & $\begin{array}{c}0.616^{* * *} \\
(0.095)\end{array}$ \\
\hline Income (logged, 3yr lag) & $\begin{array}{l}0.398^{* *} \\
(0.196)\end{array}$ & $\begin{array}{l}0.414^{* *} \\
(0.196)\end{array}$ & $\begin{array}{l}0.395^{* *} \\
(0.192)\end{array}$ & $\begin{array}{l}0.480^{* *} \\
(0.202)\end{array}$ & $\begin{array}{c}0.092 \\
(0.234)\end{array}$ & $\begin{array}{c}0.343 \\
(0.220)\end{array}$ & $\begin{array}{l}0.446^{* *} \\
(0.195)\end{array}$ & $\begin{array}{c}0.135 \\
(0.228)\end{array}$ \\
\hline Urban population (3yr lag) & $\begin{array}{c}0.012 \\
(0.016)\end{array}$ & $\begin{array}{l}-0.013 \\
(0.014)\end{array}$ & $\begin{array}{c}0.013 \\
(0.016)\end{array}$ & $\begin{array}{c}0.015 \\
(0.017)\end{array}$ & $\begin{array}{c}0.026 \\
(0.017)\end{array}$ & $\begin{array}{c}0.018 \\
(0.017)\end{array}$ & $\begin{array}{c}0.009 \\
(0.016)\end{array}$ & $\begin{array}{l}0.029^{*} \\
(0.016)\end{array}$ \\
\hline Corruption (3yr lag) & $\begin{array}{c}-0.245^{* * *} \\
(0.066)\end{array}$ & $\begin{array}{c}-0.279^{* * *} \\
(0.059)\end{array}$ & $\begin{array}{c}-0.211^{* * *} \\
(0.063)\end{array}$ & $\begin{array}{l}-0.144^{*} \\
(0.074)\end{array}$ & $\begin{array}{c}-0.257^{* * *} \\
(0.061)\end{array}$ & $\begin{array}{c}-0.257^{* * *} \\
(0.066)\end{array}$ & $\begin{array}{c}-0.254^{* * *} \\
(0.062)\end{array}$ & $\begin{array}{r}-0.298^{* * *} \\
(0.063)\end{array}$ \\
\hline CDM count (lagged) & & & $\begin{array}{c}0.001^{* * *} \\
(0.000)\end{array}$ & & & & & \\
\hline PoA count (lagged) & & & $\begin{array}{c}0.001 \\
(0.004)\end{array}$ & & & & & \\
\hline Democracy (3yr lag) & & & & $\begin{array}{l}0.540^{* *} \\
(0.234)\end{array}$ & & & & \\
\hline Political risk (3yr lag) & & & & $\begin{array}{l}-0.044 \\
(0.041)\end{array}$ & & & & \\
\hline Energy intensity (3yr lag) & & & & & $\begin{array}{l}-0.001 \\
(0.001)\end{array}$ & & & \\
\hline Particulate matter (3yr lag) & & & & & $\begin{array}{c}-0.012^{* * *} \\
(0.004)\end{array}$ & & & \\
\hline $\mathrm{CO} 2$ intensity (3yr lag) & & & & & $\begin{array}{l}-0.268 \\
(0.460)\end{array}$ & & & \\
\hline Electricity loss (3yr lag) & & & & & & $\begin{array}{l}-0.014 \\
(0.015)\end{array}$ & & \\
\hline Electricity (share of coal, 3yr lag) & & & & & & $\begin{array}{l}-0.009 \\
(0.007)\end{array}$ & & \\
\hline Trade volume (3yr lag) & & & & & & & $\begin{array}{l}-0.005 \\
(0.003)\end{array}$ & \\
\hline Industry share (3yr lag) & & & & & & & $\begin{array}{l}-0.021 \\
(0.016)\end{array}$ & \\
\hline Domestic savings rate (3yr lag) & & & & & & & $\begin{array}{c}0.007 \\
(0.011)\end{array}$ & \\
\hline Population density (people / km2, 3yr lag) & & & & & & & & $\begin{array}{c}-0.001^{* * *} \\
(0.000)\end{array}$ \\
\hline Life expectancy (years, 3yr lag) & & & & & & & & $\begin{array}{c}0.030 \\
(0.020)\end{array}$ \\
\hline Year Effects & Yes & Yes & Yes & Yes & Yes & Yes & Yes & Yes \\
\hline Region Fixed Effects & No & Yes & No & No & No & No & No & No \\
\hline Observations & 482 & 482 & 482 & 368 & 412 & 433 & 441 & 482 \\
\hline Countries & 85 & 85 & 85 & 77 & 71 & 75 & 79 & 85 \\
\hline
\end{tabular}

Standard errors in parentheses

Dependent variable: Number of CDM projects.

All models are negative binomial count models.

${ }^{*} p<0.10,{ }^{* *} p<0.05,{ }^{* * *} p<0.01$

Table 2: Main results from negative binomial count models for CDM projects. 
Main results for PoAs

\begin{tabular}{|c|c|c|c|c|c|c|c|c|}
\hline & $\begin{array}{c}(1) \\
\text { Model }\end{array}$ & $\begin{array}{c}(2) \\
\text { Model }\end{array}$ & $\begin{array}{c}(3) \\
\text { Model }\end{array}$ & $\begin{array}{c}(4) \\
\text { Model }\end{array}$ & $\begin{array}{c}(5) \\
\text { Model }\end{array}$ & $\begin{array}{c}(6) \\
\text { Model }\end{array}$ & $\begin{array}{c}(7) \\
\text { Model }\end{array}$ & $\begin{array}{c}(8) \\
\text { Model }\end{array}$ \\
\hline Population (logged, 3yr lag) & $\begin{array}{c}0.805^{* * *} \\
(0.114)\end{array}$ & $\begin{array}{c}0.848^{* * *} \\
(0.097)\end{array}$ & $\begin{array}{c}0.708^{* * *} \\
(0.134)\end{array}$ & $\begin{array}{c}0.775^{* * *} \\
(0.096)\end{array}$ & $\begin{array}{c}0.807^{* * *} \\
(0.092)\end{array}$ & $\begin{array}{c}0.759^{* * *} \\
(0.128)\end{array}$ & $\begin{array}{c}0.916^{* * *} \\
(0.140)\end{array}$ & $\begin{array}{c}0.822^{* * *} \\
(0.116)\end{array}$ \\
\hline Income (logged, 3yr lag) & $\begin{array}{l}-0.070 \\
(0.162)\end{array}$ & $\begin{array}{c}0.133 \\
(0.149)\end{array}$ & $\begin{array}{c}-0.094 \\
(0.173)\end{array}$ & $\begin{array}{c}0.002 \\
(0.140)\end{array}$ & $\begin{array}{c}-0.322 \\
(0.197)\end{array}$ & $\begin{array}{l}-0.124 \\
(0.184)\end{array}$ & $\begin{array}{c}0.179 \\
(0.233)\end{array}$ & $\begin{array}{c}-0.072 \\
(0.219)\end{array}$ \\
\hline Urban population (3yr lag) & $\begin{array}{l}-0.010 \\
(0.012)\end{array}$ & $\begin{array}{c}-0.019^{*} \\
(0.010)\end{array}$ & $\begin{array}{l}-0.009 \\
(0.013)\end{array}$ & $\begin{array}{l}-0.004 \\
(0.013)\end{array}$ & $\begin{array}{l}-0.003 \\
(0.011)\end{array}$ & $\begin{array}{l}-0.007 \\
(0.013)\end{array}$ & $\begin{array}{l}-0.009 \\
(0.015)\end{array}$ & $\begin{array}{l}-0.001 \\
(0.016)\end{array}$ \\
\hline Corruption (3yr lag) & $\begin{array}{c}-0.476^{* * *} \\
(0.124)\end{array}$ & $\begin{array}{c}-0.453^{* * *} \\
(0.103)\end{array}$ & $\begin{array}{c}-0.436^{* * *} \\
(0.132)\end{array}$ & $\begin{array}{c}-0.448^{* * *} \\
(0.117)\end{array}$ & $\begin{array}{c}-0.545^{* * *} \\
(0.109)\end{array}$ & $\begin{array}{c}-0.457^{* * *} \\
(0.130)\end{array}$ & $\begin{array}{c}-0.406^{* * *} \\
(0.145)\end{array}$ & $\begin{array}{c}-0.504^{* * *} \\
(0.129)\end{array}$ \\
\hline CDM count (lagged) & & & $\begin{array}{l}0.003^{*} \\
(0.002)\end{array}$ & & & & & \\
\hline PoA count (lagged) & & & $\begin{array}{l}-0.007 \\
(0.010)\end{array}$ & & & & & \\
\hline Democracy (3yr lag) & & & & $\begin{array}{c}0.372 \\
(0.320)\end{array}$ & & & & \\
\hline Political risk (3yr lag) & & & & $\begin{array}{c}-0.092 \\
(0.093)\end{array}$ & & & & \\
\hline Energy intensity (3yr lag) & & & & & $\begin{array}{c}-0.002^{* * *} \\
(0.001)\end{array}$ & & & \\
\hline Particulate matter (3yr lag) & & & & & $\begin{array}{l}-0.005 \\
(0.004)\end{array}$ & & & \\
\hline $\mathrm{CO} 2$ intensity (3yr lag) & & & & & $\begin{array}{c}-0.312 \\
(0.559)\end{array}$ & & & \\
\hline Electricity loss (3yr lag) & & & & & & $\begin{array}{c}-0.002 \\
(0.018)\end{array}$ & & \\
\hline Electricity (share of coal, 3yr lag) & & & & & & $\begin{array}{c}0.007 \\
(0.006)\end{array}$ & & \\
\hline Trade volume (3yr lag) & & & & & & & $\begin{array}{l}-0.000 \\
(0.003)\end{array}$ & \\
\hline Industry share (3yr lag) & & & & & & & $\begin{array}{l}-0.013 \\
(0.022)\end{array}$ & \\
\hline Domestic savings rate (3yr lag) & & & & & & & $\begin{array}{l}-0.016 \\
(0.016)\end{array}$ & \\
\hline Population density (people / km2, 3yr lag) & & & & & & & & $\begin{array}{l}-0.000 \\
(0.000)\end{array}$ \\
\hline Life expectancy (years, 3yr lag) & & & & & & & & $\begin{array}{l}-0.010 \\
(0.021)\end{array}$ \\
\hline Year Effects & Yes & Yes & Yes & Yes & Yes & Yes & Yes & Yes \\
\hline Region Fixed Effects & No & Yes & No & No & No & No & No & No \\
\hline Observations & 482 & 482 & 482 & 368 & 412 & 433 & 441 & 482 \\
\hline Countries & 85 & 85 & 85 & 77 & 71 & 75 & 79 & 85 \\
\hline
\end{tabular}

Standard errors in parentheses

Dependent variable: Number of PoA models.

All models are negative binomial count models.

${ }^{*} p<0.10,{ }^{* *} p<0.05,{ }^{* * *} p<0.01$

Table 3: Main results from negative binomial count models for PoAs. 